\title{
Association Mapping of Seedling Resistance to Spot Form Net Blotch in a Worldwide Collection of Barley
}

\author{
Prabin Tamang, Anjan Neupane, Sujan Mamidi, Timothy Friesen, and Robert Brueggeman
}

First, second, fourth, and fifth authors: Department of Plant Pathology, North Dakota State University, Fargo, ND 58108-6050; third author: Department of Plant Science, North Dakota State University, Fargo, ND 58108-6050; and fourth author: U.S. Department of AgricultureAgriculture Research Service, Red River Valley Agricultural Research Center, Cereal Crops Research Unit, Fargo, ND 58102-2765. Accepted for publication 19 November 2014.

\begin{abstract}
Tamang, P., Neupane, A., Mamidi, S., Friesen, T., and Brueggeman, R. 2015. Association mapping of seedling resistance to spot form net blotch in a worldwide collection of barley. Phytopathology 105:500-508.

Spot form net blotch (SFNB), caused by the necrotrophic fungal pathogen Pyrenophora teres f. maculata, is an important foliar disease of barley in major production regions around the world. Deployment of adequate host resistance is challenging because the virulence of $P$. teres $\mathrm{f}$. maculata is highly variable and characterized minor-effect resistances are typically ineffective against the diverse pathogen populations. A world barley core collection consisting of 2,062 barley accessions of diverse origin and genotype were phenotyped at the seedling stage with four P. teres f. maculata isolates collected from the United States (FGO), New Zealand (NZKF2), Australia (SG1), and Denmark (DEN 2.6). Of the 2,062 barley accessions phenotyped, 1,480 were genotyped with the Illumina barley iSelect chip and passed the quality controls with 5,954 polymorphic markers used for further association mapping analysis. Genome-wide association mapping was utilized to identify and map

resistance loci from the seedling disease response data and the single nucleotide polymorphism (SNP) marker data. The best among six different regression models was identified for each isolate and association analysis was performed separately for each. A total of 138 significant $(-\log 10 P$ value $>3.0)$ marker-trait associations (MTA) were detected. Using a $5 \mathrm{cM}$ cutoff, a total of $10,8,13$, and 10 quantitative trait loci (QTL) associated with SFNB resistance were identified for the FGO, SG1, NZKF2, and DEN 2.6 isolates, respectively. Loci containing from 1 to 34 MTA were identified on all seven barley chromosomes with one locus at 66 to $69 \mathrm{cM}$ on chromosome $2 \mathrm{H}$ common to all four isolates. Six distinct loci were identified by the association mapping (AM) analysis that corresponded to previously characterized SFNB resistance QTL identified by biparental population analysis (QRpt4, QRpt6, Rpt4, Rpt6, $R p t 7$, and a QTL on $4 \mathrm{H}$ that was not given a provisional gene or QTL nomenclature). The 21 putative novel loci identified may represent a broad spectrum of resistance and or susceptibility loci. This is the first comprehensive AM study to characterize SFNB resistance loci underlying broad populations of the barley host and P. teres f. maculata pathogen.
\end{abstract}

Net blotch of barley (Hordeum vulgare L.) caused by the necrotrophic fungal pathogen Pyrenophora teres Drechsler (anamorph: Drechslera teres [Sacc.] Shoem.) is a destructive pathogen in many barley-growing regions throughout the world (33). This pathogen is separated into the net and spot forms based on predominant disease symptoms with the causal agents being $P$. teres f. teres and P. teres f. maculata, respectively (57). Spot form net blotch (SFNB) has emerged as a major leaf spot disease in several barley-growing regions of the world including regions of Australia, Canada, Europe, South Africa, and recently the United States $(29,30,33,41,42,62)$. Although SFNB had previously been reported in the Upper Midwestern United States, it was not considered a problem (34). However, since it was identified in North Dakota in 2006, it has become a major concern for growers in the Northern Great Plains due to what may be increased virulence as indicated by comparison with isolates collected in other parts of the world (49).

The prevalence and increase of SFNB epidemics may be due to a combination of different factors including minimum or no-till practices, high-density cropping, cultivation of predominantly susceptible varieties, and shifts of virulence in the pathogen populations due to selection by popularly grown varieties $(33,42)$. In years when environmental conditions are conducive to disease and susceptible varieties are grown, SFNB can cause 10 to $40 \%$ yield losses in barley $(27,30,41,47)$. Chemical control, cultural

Corresponding author: R. Brueggeman;

E-mail address: Robert.Brueggeman@ndsu.edu

http://dx.doi.org/10.1094/PHYTO-04-14-0106-R

(C) 2015 The American Phytopathological Society practices, and host resistance are all commonly used to manage SFNB $(9,28,43,71)$, yet deployment of high-quality resistant cultivars would be the most efficient and environmentally friendly means of disease management.

Wide ranges of pathogenic variability in $P$. teres $\mathrm{f}$. maculata populations have been reported within and across distinct geographic regions $(21,58,62,64)$. Based on what is known in other well-characterized cereal host-Dothidiomycete necrotrophic pathosystems $(16,18,50)$, it is expected that $P$. teres produces a diversity of necrotrophic effectors (previously known as host specific/selective toxins) that target distinct susceptibility genes in barley resulting in quantitative susceptibility $(34,42)$. Resistant varieties lacking these multiple sensitivity genes are uncommon, thus sources of resistance that are effective against diverse SFNB populations are rare.

Quantitative trait loci (QTL) analysis of SFNB infection types on biparental barley mapping populations identified resistance/ susceptibility genes on barley chromosomes $2 \mathrm{H}(45), 4 \mathrm{H}(17,20)$, $5 \mathrm{H}(39), 6 \mathrm{H}(20)$, and $7 \mathrm{H}(20,68,69)$. These QTL and the markers linked with resistance may be specific to these genotypes and may represent interactions specific to narrow populations of both the host and pathogen.

Association mapping (AM) presents an alternative approach to biparental mapping that can efficiently capture diverse marker-trait associations (MTA) $(15,48,75)$. This approach has been used effectively in diverse crop plants for many traits including complex yield traits in rice (1), resistance genes/QTL in maize (32), wheat $(8,19,63)$, potato (36) and iron deficiency chlorosis (IDC) in soybean $(37,66)$, flowering time in Arabidopsis $(3,11)$, and quality 
traits in canola $(24,76)$. In barley, different marker types have been identified that are associated with phenotypes including resistance to the diseases spot blotch, Fusarium head blight, powdery mildew, and leaf rust $(6,40,54)$. Loci contributing to other important yet complexly inherited agronomic traits including malting quality $(5,22)$, yield and yield stability (31), flowering time (25), waterstress resistance (26), salt tolerance (51), and winter-hardiness (65) have also been identified utilizing AM.

The objective of this study was to use the AM approach on a large population of barley genotypes from around the world to identify loci that contribute to resistance against diverse SFNB isolates collected from four important barley-producing regions. The identification of single nucleotide polymorphism (SNP) markers associated with SFNB resistance loci and/or lacking susceptibility genes from resistant lines identified from the world barley core collection (BCC; USDA-ARS National Small Grains Collection) will facilitate the deployment of effective and durable SFNB resistance via marker-assisted selection or genome-wide selection strategies.

\section{MATERIALS AND METHODS}

Plant materials and phenotyping. A geographically diverse sample of 2,062 BCC accessions comprising cultivars, breeding lines, landraces, and genetic stocks were obtained from the National Small Grain Collection, Aberdeen, Idaho. The lines were grown in the greenhouse at the USDA, Fargo, North Dakota during 2011 and 2012. Three seeds of each barley line were planted in single cones $(3.8 \mathrm{~cm}$ diameter and $20 \mathrm{~cm}$ long) and were placed into cone racks bordered with the susceptible barley cultivar Robust. Each cone contained three seedlings and was evaluated collectively as a single replicate. Barley lines CIho-14219 and PI 67381 were used as resistant checks and the cultivar Robust was used as the susceptible check.

Four geographically diverse isolates of $P$. teres f. maculata FGOB10Ptm-1 (FGO), SG1, NZKF2, and DEN 2.6 collected in the United States, Australia, New Zealand, and Denmark, respectively, were used to evaluate the barley lines for SFNB disease reaction. Fungal inoculum preparation, inoculation, and incubation used for the AM analyses described in this manuscript were performed and described in Neupane et al. (49), which is published as an adjoining manuscript. Three independent replicates were performed for each isolate and the mean of the three replicates was considered for further analysis. Disease was evaluated 7 days after inoculation using the 1 to 5 rating scale as described in Neupane et al. (49).

Genotyping. Of the 2,417 barley accessions genotyped with the barley 9k Illumina Infinium iSELECT assay through the triticeae coordinated agriculture project (T-CAP), 2,062 of the barley accessions were evaluated for their reaction to the $P$. teres $\mathrm{f}$ maculata isolates (49). The genotyping was performed and described by Muñoz-Amatriaín et al. (46) and the data were obtained from The Triticeae Toolbox (T3) website (http://malt.pw. usda.gov/t3/sandbox/barley/). For this AM analysis we utilized the 6,244 quality SNPs that passed the quality control criteria and 1,480 unique iCore spring barley lines that were previously described (46). Throughout the manuscript the analyses relied on the marker positions, which were previously determined and published as the iSelect consensus map (46).

AM. Imputation and marker properties. All missing genotypic data were imputed using a "likelihood" based imputation with default settings in fastPhase 1.3 (55). The minor allele frequency (MAF) for markers was estimated using the FREQ procedure in SAS 9.3 and the markers that had MAF $<5 \%$ were removed from further analysis. The structure, kinship, and AM were also performed separately utilizing all the markers, the markers that have MAF $>1 \%$ and the markers $>5 \%$ MAF which are reported in the manuscript. From the results, there were very minor changes between the analyses in terms of significant markers or the number of QTL identified.
Linkage disequilibrium $(L D)$ and $L D$ decay. $L D$ was estimated as the squared allele frequencies correlation $\left(R^{2}\right)$ for each of the pair-wise comparison of the markers using the Corr procedure in SAS 9.3. Linkage disequilibrium decay graphs were plotted with genetic distance (centimorgans) versus $R^{2}$ for all interchromosomal marker pairs using nonlinear regression (53). The expected decay of LD was estimated using the formula described by Mamidi et al. (37)

Population structure, principal component analysis (PCA), and relationship matrix. To prevent linkage bias in estimation of population structure (Q), PCA and relationship matrix (K-matrix), a subset of markers that had an LD $<0.5$ with every other marker combination were used (67). STRUCTURE 2.3 was used to estimate the number of subpopulations. The admixture model was used with a burn-in of 20,000 and 50,000 iterations for subpopulation numbers $(k)$ ranging from 1 to 15 considering the allele frequencies to be independent. Five runs for each $k$ value were performed and the posterior probability was determined for each run. The optimum number of subpopulations was determined using the $\Delta k$ approach (12) implemented in STRUCTURE HARVESTER (10).

PCA was performed in SAS 9.3 to estimate PCs that controlled the population structure in the regression model. The number of PCs that explained $\sim 25 \%$ of the cumulative variation in the population were selected to be included as cofactors in the association analysis $(37,60)$. An identity by state (IBS) matrix $(73)$ to control the population relatedness was estimated as a Gower similarity ratio implemented in the distance procedure in SAS 9.3.

MTA model testing. Six different linear regression models were tested for MTAs (Naive, PC, Q, kin, PC+kinship, Q+kinship [37]). Three models that did not have kinship were estimated in SAS 9.3 and three models that had the kinship matrix as a random effect were estimated using GEMMA 0.90 (74). Three general-linear models (GLMs) considered only the fixed effects while the remaining three mixed-linear models (MLMs) considered both the fixed and random effects. The underlying linear equation for the sixth model was

$$
\mathrm{Y}=\mathrm{X} \alpha+\mathrm{Q} \beta+\mathrm{Kv}+\varepsilon
$$

In this model, $\mathrm{Y}$ was a vector for phenotypic observation, $\mathrm{X}$ was a matrix of alleles of the markers, $\alpha$ was the fixed effects related to the SNP markers, $Q$ was the population structure, $\beta$ was a vector of the fixed effects related to population structure, $K$ was the subpopulation numbers, $v$ was a vector of the random effects related to the relatedness among the individuals, and $\varepsilon$ was a vector of the residual effects. For each model, the positive false discovery rate (pFDR) was estimated for all markers using the PROC MULTTEST in SAS 9.3 to correct for multiple MTA (61). For the selection of best model, a rank based mean square difference (MSD) was used (37) based on the suggestion of Yu et al. (72) of random errors. MSD values were calculated between the observed $P$ values and expected $P$ values. Expected $P$ values were estimated by dividing the rank of observed $P$ value with number of makers used in this study. The model with the lowest MSD value was considered the best model. Markers were considered significant if the $P$ value was less than 0.001 . The amount of phenotypic variation $\left(R^{2}\right)$ was estimated for each significant marker using a simple regression using the REG procedure in SAS 9.3. Multiple $R^{2}$ values for significant markers were calculated using stepwise regression implemented in the Reg procedure in SAS 9.3 (38). The allelic means of the significant markers were estimated in SAS 9.3 using the Means procedure. Further, a QTL was defined as the region that harbors multiple significant markers $(P<0.001)$ within a distance at which the whole genome LD decay stabilizes. The position of the significant markers was obtained from a core consensus map developed by Muñoz-Amatriaín et al. (46). 


\section{RESULTS}

Phenotypic analysis across barley accession. A total of 2,062 spring BCC accessions were evaluated for their reaction to the four $P$. teres f. maculata isolates (FGO, NZKF2, SG1, and DEN 2.6) by Neupane et al. (49). The manuscript describing the phenotypic analyses and results is published as an adjoining manuscript (49). Of the 2,062 accessions reported in Neupane et al. (49), only 1,480 accessions were utilized in our analysis due to marker data not passing quality control and redundant genotypes being eliminated as determined by Muñoz-Amatriaín et al. (46).

Marker properties. Of the 2,062 barley accessions evaluated for their reaction to the $P$. teres f. maculata isolates (49), 1,947 barley accessions were genotyped with a total of 6,244 SNP markers. Of the 1,947 spring barley accessions genotyped, 467 were removed due to genetic redundancy or inconsistent passport data, leaving 1,480 spring barley accessions in the AM analysis (46). Approximately $0.43 \%$ of the missing genotypic data were imputed. Out of 6,244 SNPs, only 5,954 markers that had an MAF $>0.05$ were used for further analysis. Based on the LD coefficient $\left(r^{2}\right.$; correlation squared between markers), 4,402 markers that had LD $>0.5$ with at least one other marker were removed for estimating the confounding factors for population structure and relatedness.

LD. A nonlinear regression model estimates the average genome-wide LD decay across the genome using the interchromosomal comparison of LD. The whole genome-wide LD decay was extended up to $5 \mathrm{cM}$ at $r^{2} \geq 0.1$ (Fig. 1).

Population structure, PCA, and relationship matrix. A subset of 1,842 markers that had an $\mathrm{LD}<0.5$ with any other marker in the subset was used to analyze the population structure, PCA, and relationship matrix. The Bayesian-based clustering approach in STRUCTURE revealed eight subpopulations by the $\Delta k$ approach (Fig. 2). The number of barley accessions in each subpopulation varied between 94 (subpopulation 4) and 238 (subpopulation 2). Accounting for this population structure in the AM analysis reduces the number of false-positive QTL identified.

Six PCs that explained about $25 \%$ of the variation were used as cofactors in the mixed model. The first PC explained $7.92 \%$ of the variation followed by PC2 that explained $6.12 \%$.

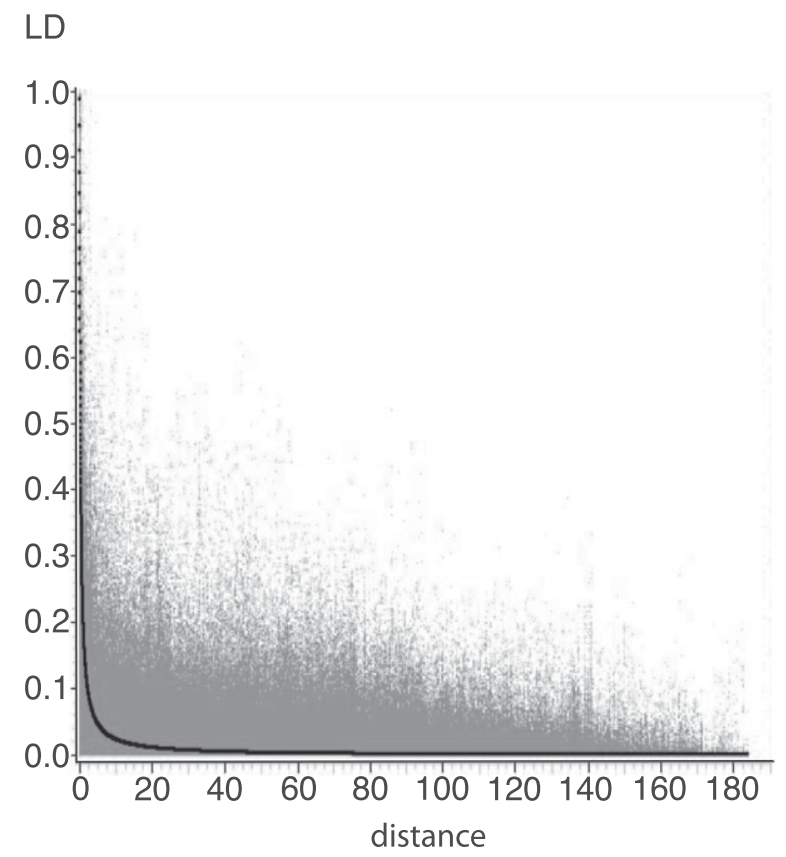

Fig. 1. Pattern of linkage disequilibrium (LD) decay created by plotting $r^{2}$ values against the genetic distance $(\mathrm{cM})$ for the whole genome. The curve shows nonlinear regression of $r^{2}$ on a weighted genetic distance.
AM analyses. FGO isolate. For the AM analyses, the four isolates were analyzed separately and the average score of the three replicates for each isolate was used for the phenotypic data. Out of the six models tested for the FGO isolate, the model with only kinship (IBS) was the best with an MSD of 0.001. A total of 29 SNP markers were found to be significantly associated with resistance against isolate FGO at a cutoff of $P<0.001$. The 29 markers were located on all seven barley chromosomes, with one marker on chromosome $1 \mathrm{H}$, two on $2 \mathrm{H}$, six on $3 \mathrm{H}$, one on $4 \mathrm{H}$, two on $5 \mathrm{H}$, four on $6 \mathrm{H}$, and four on $7 \mathrm{H}$ (Table 1). There was no marker position information for the remaining nine markers. The $P$ values of significant markers had a range of 4.37E-09 to 3.43E-04. The MAF for the significant markers ranged from 7.91 to 49.80 . The $R^{2}$ (phenotypic variation) for all significant markers was up to $4.5 \%$ (Table 1). Based on a cutoff of $5 \mathrm{cM}$, a total of 10 loci associated with resistance were identified. Of the loci associated with resistance, one was identified on chromosome $1 \mathrm{H}(114.3 \mathrm{cM})$, two on chromosome $2 \mathrm{H}(69.55$ and $137.44 \mathrm{cM})$, one on $3 \mathrm{H}(99.26$ to $99.66 \mathrm{cM})$, one on $4 \mathrm{H}(99.68 \mathrm{cM})$, one on $5 \mathrm{H}(31.86 \mathrm{cM})$, one on $6 \mathrm{H}$ (59.01 to $60.21 \mathrm{cM}$ ), and three on $7 \mathrm{H}$ (26.35 to 26.92, 109.0, and $133.84 \mathrm{cM}$ ) (Fig. 3D). From the stepwise regression, 17 markers were included in the model and cumulatively explained $18.78 \%$ of the phenotypic variation. All 10 loci associated with resistance contained markers that were included in the stepwise regression.

SG1 isolate. For the SG1 isolate, the model with structure and kinship (IBS) was the best model with $\mathrm{MSD}=0.000668$. A total of 17 markers were significant of which two are on $1 \mathrm{H}$, five on $2 \mathrm{H}$, one on $3 \mathrm{H}$, two on $4 \mathrm{H}$, two on $5 \mathrm{H}$, and one on $6 \mathrm{H}$. The remaining four markers did not have any position information (Table 2). The MAF values for all significant markers had a range of 6.08 to 32.97. The $P$ values for the significant markers ranged between $1.60 \mathrm{E}-05$ and $3.76 \mathrm{E}-05$. The $R^{2}$ (phenotypic variation) for all significant markers was up to $5.68 \%$ (Table 2 ). There were eight loci identified that contained markers significantly associated with resistance with two being located on chromosome $1 \mathrm{H}(50$ and $98.45 \mathrm{cM})$, one on $2 \mathrm{H}(65.71$ to $66.11 \mathrm{cM})$, one on $3 \mathrm{H}(88.17 \mathrm{cM})$, two on $4 \mathrm{H}(32.43$ and $47.17 \mathrm{cM})$, one on $5 \mathrm{H}(31.86 \mathrm{cM})$ and one on $6 \mathrm{H}(101.83 \mathrm{cM})$ (Fig. 3C). From the stepwise regression, seven markers were included in the model and cumulatively explained $7.74 \%$ of the phenotypic variation.

NZKF2 isolate. Out of the six models tested, the best model for the isolate NZKF2 data were structure and kinship (IBS) with an $\mathrm{MSD}=0.001829$. From the 54 markers identified as significant, two were located on $2 \mathrm{H}, 12$ on $3 \mathrm{H}, 21$ on $4 \mathrm{H}$, one on $5 \mathrm{H}$, three on $6 \mathrm{H}$, and seven on $7 \mathrm{H}$ (Table 3 ). The remaining eight markers did not have

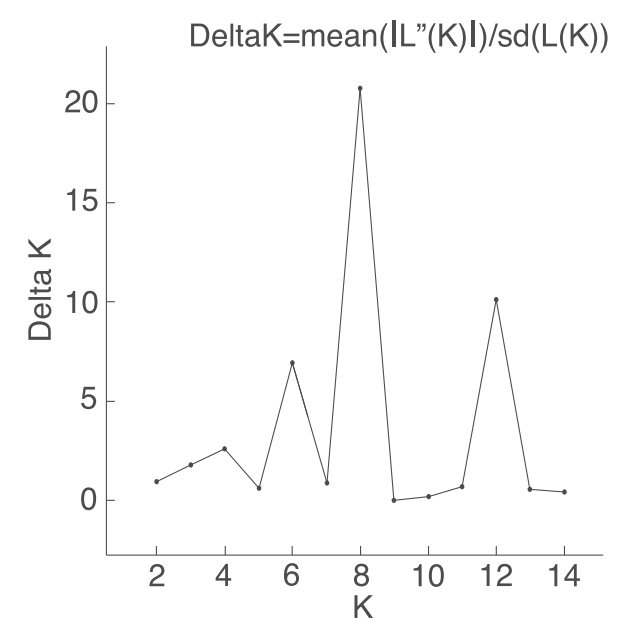

Fig. 2. A graph with $\Delta k$ and number of subpopulations. The Bayesian-based clustering approach in STRUCTURE revealed eight subpopulations by the $\Delta k$ approach (12). The peak represents the appropriate number of subpopulation. 
marker position information. The $P$ values of the markers had a range of 3.75E-12 to 9.77E-04. The MAF values for all significant markers ranged from 5.14 to 49.19 . The $R^{2}$ (phenotypic variation) for all significant markers was up to $15.97 \%$ (Table 3). A total of 13 loci associated with resistance to NZKF2 were identified, two on $2 \mathrm{H}$ $(23.76,69 \mathrm{cM})$, three on $3 \mathrm{H}(53.4,99.26$ to 103.86 , and $153.39 \mathrm{cM})$, three on $4 \mathrm{H}$ (53.67 to $57.32,103.48$ to 103.58 , and $117.13 \mathrm{cM})$, one on $5 \mathrm{H}(111.56 \mathrm{cM})$, one on $6 \mathrm{H}(59.21 \mathrm{cM})$, and three on $7 \mathrm{H}(78.07$, 133.84 , and 145.68 to $150.36 \mathrm{cM}$ ) (Fig. 3B). From the stepwise regression, 23 markers were included in the model and together explained $44.35 \%$ of the phenotypic variation. All 113 loci containing markers associated with resistance were included in the stepwise regression.

DEN 2.6 isolate. Out of the six models tested for the DEN 2.6 isolate, the best model identified was structure and kinship (IBS) with an MSD $=0.000577$. A total of 38 markers were highly significant with one marker on $1 \mathrm{H}$, one marker on $2 \mathrm{H}$, four markers on $3 \mathrm{H}, 20$ on $4 \mathrm{H}$, one on $5 \mathrm{H}$, three on $6 \mathrm{H}$, and one on $7 \mathrm{H}$ (Table 4 ). The remaining seven markers did not have any marker position information. The $P$ values ranged between $9.65 \mathrm{E}-15$ and $4.99 \mathrm{E}-04$. The MAF values for all significant markers ranged from 5.16 to 46.22. The $R^{2}$ (phenotypic variation) for all significant markers was up to $14.78 \%$ (Table 4). Analysis of the isolate DEN 2.6 data identified a total of six loci with markers associated with resistance with one locus being on $1 \mathrm{H}(88.25 \mathrm{cM})$, one on $2 \mathrm{H}(69 \mathrm{cM})$, three on $3 \mathrm{H}(53.42,65.16$, and 150.19 to $154.47 \mathrm{cM})$, three on $4 \mathrm{H}(53.77$ to $54.95,59.22$, and 96.6 to $96.99 \mathrm{cM})$, one on $5 \mathrm{H}(111.56 \mathrm{cM})$, one on $6 \mathrm{H}(59.21 \mathrm{cM})$, and one on $7 \mathrm{H}(0 \mathrm{cM})($ Fig. 3A). From the stepwise regression, 20 markers were included in the stepwise regression model. The significant markers included in the stepwise regression

TABLE 1 . Single nucleotide polymorphism markers significantly associated with resistance/susceptibility to Pyrenophora teres f. maculata isolate FGO

\begin{tabular}{|c|c|c|c|c|c|c|}
\hline Marker & $\mathrm{Chr}^{\mathrm{a}}$ & $\mathrm{cM}^{\mathrm{a}, \mathrm{b}}$ & $R^{2}(\%)^{\mathrm{c}}$ & $\mathrm{MAF}^{\mathrm{d}}$ & $P$ value ${ }^{\mathrm{e}}$ & $\mathrm{pFDR}^{\mathrm{f}}$ \\
\hline 11_21392 & $1 \mathrm{H}$ & 114.3 & 0.0330 & 13.446 & 3.09 & 0.152 \\
\hline 12_11504 & $2 \mathrm{H}$ & 69.55 & 0.0185 & 9.392 & 3.02 & 0.170 \\
\hline SCRI_RS_155161 & $2 \mathrm{H}$ & 137.44 & 0.0003 & 31.62 & 3.75 & 0.069 \\
\hline SCRI_RS_221787 & $3 \mathrm{H}$ & 99.26 & 0.0006 & 26.55 & 4.24 & 0.039 \\
\hline SCRI_RS_164704 & $3 \mathrm{H}$ & 99.26 & 0.0004 & 26.42 & 3.73 & 0.069 \\
\hline SCRI_RS_133339 & $3 \mathrm{H}$ & 99.56 & 0.0002 & 27.64 & 3.67 & 0.069 \\
\hline SCRI_RS_211929 & $3 \mathrm{H}$ & 99.66 & 0.0007 & 27.43 & 4.25 & 0.039 \\
\hline SCRI_RS_235791 & $3 \mathrm{H}$ & 99.66 & 0.0006 & 27.5 & 4.13 & 0.042 \\
\hline 12_30423 & $3 \mathrm{H}$ & 99.66 & 0.0013 & 32.43 & 3.56 & 0.080 \\
\hline SCRI_RS_131671 & $4 \mathrm{H}$ & 99.68 & 0.0044 & 45.473 & 3.12 & 0.152 \\
\hline SCRI_RS_108416 & $5 \mathrm{H}$ & 31.86 & 0.0033 & 39.26 & 4.66 & 0.038 \\
\hline SCRI_RS_205100 & $5 \mathrm{H}$ & 31.86 & 0.0033 & 39.39 & 4.27 & 0.039 \\
\hline SCRI_RS_213566 & $6 \mathrm{H}$ & 59.01 & 0.0316 & 26.892 & 3.11 & 0.152 \\
\hline SCRI_RS_188243 & $6 \mathrm{H}$ & 59.21 & 0.0279 & 8.24 & 8.36 & 0.000 \\
\hline SCRI_RS_186193 & $6 \mathrm{H}$ & 59.21 & 0.0252 & 10.27 & 6.25 & 0.001 \\
\hline 12_30144 & $6 \mathrm{H}$ & 60.21 & 0.0417 & 32.64 & 4.22 & 0.039 \\
\hline $12 \_30530$ & $7 \mathrm{H}$ & 26.35 & 0.0192 & 36.01 & 3.55 & 0.080 \\
\hline SCRI_RS_179528 & $7 \mathrm{H}$ & 26.92 & 0.0091 & 41.689 & 3.08 & 0.152 \\
\hline SCRI_RS_112204 & $7 \mathrm{H}$ & 109 & 0.0086 & 49.8 & 3.76 & 0.069 \\
\hline SCRI_RS_202130 & $7 \mathrm{H}$ & 133.84 & 0.0191 & 35.81 & 4.44 & 0.039 \\
\hline SCRI_RS_195914 & N/A & N/A & 0.0258 & 11.28 & 4.04 & 0.047 \\
\hline SCRI_RS_136604 & N/A & N/A & 0.0372 & 8.72 & 3.77 & 0.069 \\
\hline SCRI_RS_45644 & N/A & N/A & 0.0450 & 7.91 & 3.67 & 0.069 \\
\hline SCRI_RS_237419 & N/A & N/A & 0.0183 & 33.85 & 3.51 & 0.083 \\
\hline SCRI_RS_224297 & N/A & N/A & 0.0185 & 33.78 & 3.46 & 0.088 \\
\hline SCRI_RS_158011 & N/A & N/A & 0.0185 & 33.716 & 3.37 & 0.105 \\
\hline SCRI_RS_188305 & N/A & N/A & 0.0361 & 8.784 & 3.34 & 0.107 \\
\hline SCRI_RS_209824 & N/A & N/A & 0.0418 & 32.973 & 3.28 & 0.118 \\
\hline SCRI_RS_156620 & N/A & N/A & 0.0000 & 41.959 & 3.16 & 0.149 \\
\hline
\end{tabular}

a N/A indicates that the marker was not anchored to the consensus map.

b Genetic distances in centimorgans (cM).

c Phenotypic variation explained by individual markers.

${ }^{d}$ Minor allele frequency (MAF).

e $-\log 10(P$ value $)$ for each individual marker calculated from the QK mixed model.

${ }^{f}$ Positive false discovery rate ( $\left.\mathrm{pFDR}\right)$. together explained $37.1 \%$ of the phenotypic variation for this isolate and markers from all 10 loci were included.

\section{DISCUSSION}

The BCC represents a worldwide base of diversity allowing for the use of historical recombination for association mapping of variation in responses to isolates of $P$. teres $\mathrm{f}$. maculata; the cause of SFNB. The distribution of SFNB infection types across the BCC accessions analyzed indicated that susceptibility or resistance is polygenic in nature consistent with previous studies $(33,44,68,69)$. The phenotyping data coupled with robust genotyping of the BCC accessions challenged with diverse $P$. teres f. teres isolates allowed for the capture of multiple MTAs. This AM analysis is the first report of AM of SFNB resistance in barley and includes worldwide diversity of the host challenged with isolates from regions around the globe.

The power of a mixed model to harness historical recombination events using AM is dependent on phenotyping, markers, population structure, and relatedness, thus requiring the testing of multiple models to determine which ones performed best for the specific isolate being analyzed $(4,14,37)$. The mixed model which accounted for both population structure (Q) and kinship (K) was the best model for the Australian isolate SG1, the New Zealand isolate NZKF2, and the Denmark isolate DEN 2.6, whereas the model which only accounted for kinship was the best model for the U.S. isolate FGO. The AM analyses utilizing these models identified a total of 138 significant $(-\log 10(P)$ value $>3.0)$ MTAs. Using a $5 \mathrm{cM}$ cutoff to define a QTL, a total of 10, 8, 13, and 10 loci associated with SFNB resistance/susceptibility were identified for FGO, SG1, NZKF2, and DEN 2.6, respectively. A total of 10 of the 41 loci identified were common to two or more of the isolates, resulting in a total of 27 distinct loci with six consistent to previously identified QTL and the remaining 21 representing putative novel SFNB resistance loci.

The analysis for MTAs was also conducted utilizing the more stringent positive false discovery rate (pFDR) $<0.1$ (Tables 1 to 4 ). These analyses resulted in a reduction from the 138 significant markers using $P$ value down to 105 significant markers using pFDR. The more stringent pFDR analysis reduced the number of significant loci identified to 7, 1, 13, and 7 loci for FGO, SG1, NZKF2, and DEN 2.6, respectively. The reduction of the FGO, SG1, and DEN 2.6 isolates from 10, 8 and 10 to 7, 1, 7 significant loci, respectively, is due to the higher stringency of pFDR analysis. The MTAs defining the locus on $\mathrm{Ch} 2 \mathrm{H}$ at $\sim 69 \mathrm{cM}$ (Fig. 3) was the one locus that was common to all four isolates and remained significant for SG1 using both $P$ value and pFDR. Two other markers at one of the seven remaining loci that was significant using $P$ value and were not significant with pFDR corresponded to the previously identified Rpt6 QTL (Fig. 3). Since these two independent phenotyping data sets both identified these specific MTAs corresponding to a known resistance locus, it is unlikely that the loss of this locus using pFDR was due to a false association when using the $P$ value. Thus, the $P$ value analysis that identified two significant common markers between isolates SG1 and FGO indicates that these two isolates may carry effectors that target common host susceptibility genes underlying this locus, but these MTAs were eliminated when the pFDR was used. This suggested that when running association analyses on a diverse host population for complex quantitative traits the stringent $\mathrm{pFDR}$ may eliminate some important MTAs or loci so here we reported all loci identified using the less stringent $P$ value analyses. However, the pFDR values were left in the tables for comparison.

We detected MTAs that corresponded to six loci on four chromosomes that were previously identified and mapped at low resolution by biparental QTL analyses. A common locus for isolates NZKF2 and DEN 2.6 was identified on chromosome $4 \mathrm{H}$ at position 53.67 to $59.22 \mathrm{cM}$ explaining up to $16 \%$ of the phenotypic variation. There are 36 significant markers for the NZKF2 and DEN 2.6 
isolates at this locus with the markers for NZKF2 having the highest significance of any MTAs in the analysis. Neither of the genes underlying these SNP markers are predicted to encode susceptibility target/biotrophic resistance-like proteins, as characterized in the Stagonospora nodorum-wheat pathosystem (13). However, there are other significant SNP markers in the region in resistance-like genes such as leucine-rich receptor-like protein kinases. This region resides in the same region as QRpts 4 as reported by Grewal et al. (20), which explained $21 \%$ of the phenotypic variation in a doubled haploid (DH) population of CDC Dolly (susceptible) and TR251 (resistant). The QTL region reported by Friesen et al. (17) on chromosome $4 \mathrm{H}$ using the NZKF2 isolate on the DH population of SM89010/Q21861 is proximal to this region, but is close to the NZKF2, DEN 2.6, and FGO common locus at 99.68 to $103.58 \mathrm{cM}$ that explained $8.3 \%$ of the phenotypic variation and the NZKF2 specific locus at $117.13 \mathrm{cM}$ explaining $11.7 \%$ of the phenotypic variation.
Using the FGO and SG1 isolates, two identical markers were identified (SCRI_RS_108416 and SCRI_RS_205100) on chromosome $5 \mathrm{H}$ at position 31.86 that explained $0.1 \%$ of the phenotypic variation. This locus is probably the QRpt6 QTL reported by Manninen et al. (39) that explained up to $84 \%$ of the phenotypic variation in a $\mathrm{DH}$ population derived from Rolfi (susceptible) and CI 9819 (resistant) using Finnish isolates. The reason for low phenotypic variation in our study might be due to the different populations and different isolates.

The MTAs detected on chromosome $6 \mathrm{H}$ at position 58.9 to $60.2 \mathrm{cM}$ were common for DEN 2.6, NZKF2, and FGO and the phenotypic variation explained by this common locus was as high as $4 \%$. This locus is located at a similar genetic interval as the previously described QRpt6 QTL reported by Grewal et al. (20) in the Canadian breeding line TR251. This locus from line TR251 also exhibited resistance to net form net blotch (NFNB). Qamar et al. (52) also identified an NFNB resistance locus at the QRpt6 region

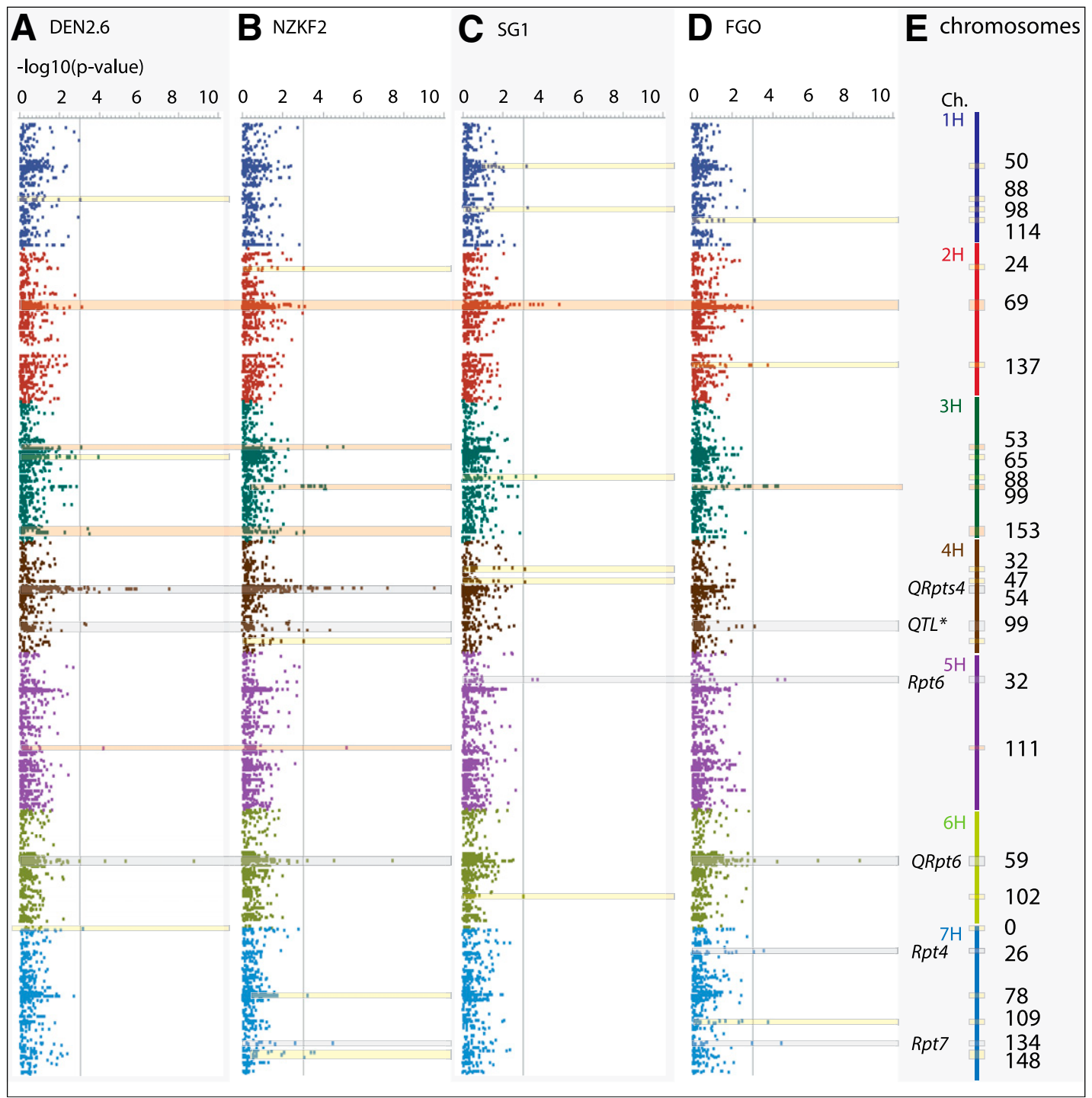

Fig. 3. Association mapping of spot form net blotch (SFNB) isolates on the world barley core collection (BCC). Panels A to D show Manhattan plots generated from the disease reaction to four isolates of Pyrenophora teres f. maculata: A, isolate DEN 2.6 from Denmark; B, isolate NZKF2 from New Zealand; C, isolate SG1 from Australia; and D, isolate FGO from Fargo, ND (United States). All colored pixels represent single nucleotide polymorphism markers from the 9K Illumina genotyping on the seven barley chromosomes; from blue at the top as chromosome $1 \mathrm{H}$ and light blue at the bottom as chromosome $7 \mathrm{H}$. All markers above the LOD threshold of $3.0(P$ value $(-\log 10))$ were significantly associated with SFNB resistance/susceptibility. Resistance/susceptibility loci are designated as colored bars. Orange bars are loci common to several isolates, yellow are specific to a single isolate, and gray are loci corresponding to quantitative trait loci (QTL) regions previously identified by biparental mapping. E, A map of the seven barley chromosomes is shown as colored vertical bars with chromosome designations given. The 27 resistance loci detected in these analyses are shown as horizontal bars with approximate centimorgan values given to the left and known SFNB resistance genes/QTL nomenclatures provided on the right. 
on chromosome $6 \mathrm{H}$, cosegregating with microsatellite marker Bmag0173 and Bmag0807 (52). The highly significant markers SCRI_RS_188243 (gene MLOC_73854.4) and SCRI-RS-186193 (gene MLOC_16471.1) for the FGO, NZKF2, and DEN 2.6 isolates were identified on chromosome $6 \mathrm{H}$ at $59.2 \mathrm{cM}$. These two common markers, with the gene designations MLOC_73854.4 and MLOC_16471.1, are predicted to encode an unknown protein and an SPla/RYanodine receptor (SPRY) domain-containing protein, respectively. These two markers explained up to 2.8 and $2.3 \%$ of the phenotypic variation, respectively. From this AM panel data, it is premature to consider the genes containing these SNP markers as candidate host susceptibility or resistance genes; however, there are other markers and genes annotated in the region that code for R-like genes including NBS-LRR and serine/threonine protein kinase genes.

The Rpt4 gene located on the long arm of chromosome $7 \mathrm{H}$ was the first SFNB resistance gene described in the cultivar Galleon. Later, Rpt4 was mapped in several breeding lines and varieties such as CI9214, Keel, Chebec, and Tilga $(68,69)$; however, this gene was not utilized in Australian breeding programs due to its lack of effectiveness at the adult plant stage (68). We identified one locus at the Rpt4 region (26.4 to $26.9 \mathrm{cM}$ ) that explained up to $3 \%$ of the phenotypic variation with the U.S. isolate FGO, but interestingly was not detected using the Australian isolate SG1. This QTL may represent the seedling resistance gene Rpt4 identified on the long arm of chromosome $7 \mathrm{H}$ (position 6.9 to $25.6 \mathrm{cM}$ ) flanked by the restriction fragment length polymorphic markers Xpsr117(D) and Xcdo673 (68). A minor effect locus at position $0.7 \mathrm{cM}$ was also detected on chromosome 7H against isolate DEN 2.6 and a locus common to isolates FGO and NZKF2 was identified at position 132.6 to $133.8 \mathrm{cM}$ explaining up to $5.1 \%$ of the phenotypic variation. We also identified two other loci at $109 \mathrm{cM}$ and 145.68 to $150.36 \mathrm{cM}$ close to this region that were identified using the FGO and NZKF2 isolates, respectively. Any of these loci could be the same as the QRpt7 gene reported by Williams et al. (69) on chromosome $7 \mathrm{H}$ at position 116 to $134 \mathrm{cM}$. The identification of all six well-characterized SFNB resistance loci suggests that these AM analyses were robust and that the remaining 21 novel resistance loci may represent putative new sources of SFNB resistance or lack of susceptibility that could also be utilized in resistance breeding efforts.

TABLE 2. Single nucleotide polymorphism markers significantly associated with resistance/susceptibility to Pyrenophora teres f. maculata isolate SG1

\begin{tabular}{llccccc}
\hline Marker & $\mathrm{Chr}^{\mathrm{a}}$ & $\mathrm{cM}^{\mathrm{a}, \mathrm{b}}$ & $R^{2}(\%)^{\mathrm{c}}$ & $\mathrm{MAF}^{\mathrm{d}}$ & $P$ value $^{\mathrm{e}}$ & $\mathrm{pFDR}^{\mathrm{f}}$ \\
\hline 11_20810 & $1 \mathrm{H}$ & 50.00 & 0.001 & 38.649 & 3.17 & 0.271 \\
SCRI_RS_188909 & $1 \mathrm{H}$ & 98.45 & 0.008 & 27.365 & 3.22 & 0.262 \\
SCRI_RS_151535 & $2 \mathrm{H}$ & 65.71 & 0.000 & 27.905 & 3.98 & 0.147 \\
SCRI_RS_175065 & $2 \mathrm{H}$ & 65.81 & 0.000 & 24.73 & 3.76 & 0.157 \\
SCRI_RS_154617 & 2H & 66.11 & 0.000 & 23.58 & 4.80 & 0.064 \\
11_10325 & 2H & 66.11 & 0.000 & 24.73 & 3.52 & 0.181 \\
11_10733 & 2H & 66.11 & 0.000 & 24.865 & 3.36 & 0.207 \\
SCRI_RS_159340 & 3H & 88.17 & 0.042 & 10.068 & 3.65 & 0.157 \\
12_30907 & 4H & 32.43 & 0.005 & 11.351 & 3.11 & 0.287 \\
SCRI_RS_9296 & 4H & 47.17 & 0.003 & 20.338 & 3.09 & 0.287 \\
SCRI_RS_108416 & 5H & 31.86 & 0.008 & 39.257 & 3.71 & 0.157 \\
SCRI_RS_205100 & 5H & 31.86 & 0.008 & 39.392 & 3.48 & 0.181 \\
SCRI_RS_151574 & 6H & 101.83 & 0.000 & 30.946 & 3.04 & 0.300 \\
SCRI_RS_209824 & N/A & N/A & 0.057 & 32.97 & 4.65 & 0.064 \\
SCRI_RS_139690 & N/A & N/A & 0.020 & 6.08 & 4.42 & 0.071 \\
11_20336 & N/A & N/A & 0.000 & 49.662 & 3.82 & 0.157 \\
SCRI_RS_8401 & N/A & N/A & 0.001 & 47.568 & 3.45 & 0.181 \\
\hline
\end{tabular}

a N/A indicates that the marker was not anchored to the consensus map.

b Genetic distances in centimorgans (cM).

c Phenotypic variation explained by individual markers.

d Minor allele frequency (MAF).

e $-\log 10(P$ value $)$ for each individual marker calculated from the QK mixed model.

f Positive false discovery rate ( $\mathrm{pFDR})$.
The last remaining SFNB QTL previously reported by Molnar et al. (45) was reported as a major resistance gene on chromosome $2 \mathrm{H}$. However, the location was not precise so it is difficult to determine if any of the $2 \mathrm{H}$ loci identified in this AM analysis are the same as that reported by Molnar et al. (45). We detected MTAs on chromosome $2 \mathrm{H}$ at $\sim 24,69$, and $137 \mathrm{cM}$ (Fig. 3). The locus identified at $\sim 69 \mathrm{cM}$ was the only locus identified with all four isolates tested (Fig. 3), and explained up to $5.6 \%$ of the phenotypic variation. Thus, this may be the best candidate for the major resistance reported by Molnar et al. (45), but due to the low

TABLE 3. Single nucleotide polymorphism markers significantly associated with resistance/susceptibility to Pyrenophora teres f. maculata isolate NZKF2

\begin{tabular}{|c|c|c|c|c|c|c|}
\hline Marker & $\mathrm{Chr}^{\mathrm{a}}$ & $\mathrm{cM}^{\mathrm{a}, \mathrm{b}}$ & $R^{2}(\%)^{\mathrm{c}}$ & $\mathrm{MAF}^{\mathrm{d}}$ & $P$ value ${ }^{\mathrm{e}}$ & $\mathrm{pFDR}^{\mathrm{f}}$ \\
\hline SCRI_RS_152744 & $2 \mathrm{H}$ & 23.76 & 0.004 & 39.46 & 3.03 & 0.095 \\
\hline $12 \_20878$ & $2 \mathrm{H}$ & 69 & 0.071 & 5.14 & 3.12 & 0.084 \\
\hline SCRI_RS_127994 & $3 \mathrm{H}$ & 53.42 & 0.083 & 25.2 & 5.03 & 0.005 \\
\hline $12 \_30785$ & $3 \mathrm{H}$ & 53.42 & 0.084 & 24.19 & 4.21 & 0.019 \\
\hline SCRI_RS_221787 & $3 \mathrm{H}$ & 99.26 & 0.001 & 26.55 & 3.41 & 0.061 \\
\hline SCRI_RS_164704 & $3 \mathrm{H}$ & 99.26 & 0.001 & 26.42 & 3.25 & 0.071 \\
\hline SCRI_RS_225641 & $3 \mathrm{H}$ & 99.46 & 0.002 & 27.64 & 3.01 & 0.098 \\
\hline SCRI_RS_133339 & $3 \mathrm{H}$ & 99.56 & 0.001 & 27.64 & 3.84 & 0.030 \\
\hline SCRI_RS_235791 & $3 \mathrm{H}$ & 99.66 & 0.001 & 27.5 & 4.11 & 0.020 \\
\hline SCRI_RS_211929 & $3 \mathrm{H}$ & 99.66 & 0.001 & 27.43 & 3.95 & 0.025 \\
\hline $12 \_30423$ & $3 \mathrm{H}$ & 99.66 & 0.001 & 32.43 & 3.56 & 0.052 \\
\hline SCRI_RS_167825 & $3 \mathrm{H}$ & 103.46 & 0.048 & 29.46 & 4.14 & 0.020 \\
\hline SCRI_RS_163092 & $3 \mathrm{H}$ & 103.86 & 0.048 & 28.04 & 4.05 & 0.021 \\
\hline SCRI_RS_156315 & $3 \mathrm{H}$ & 153.39 & 0.030 & 42.7 & 3.07 & 0.091 \\
\hline SCRI_RS_157310 & $4 \mathrm{H}$ & 53.67 & 0.011 & 37.16 & 3.38 & 0.061 \\
\hline SCRI_RS_128723 & $4 \mathrm{H}$ & 54.66 & 0.139 & 30.95 & 5.93 & 0.001 \\
\hline SCRI_RS_155554 & $4 \mathrm{H}$ & 54.66 & 0.119 & 30.41 & 5.56 & 0.002 \\
\hline SCRI_RS_208828 & $4 \mathrm{H}$ & 54.66 & 0.154 & 37.43 & 5.53 & 0.002 \\
\hline SCRI_RS_221172 & $4 \mathrm{H}$ & 54.66 & 0.137 & 35.2 & 4.99 & 0.005 \\
\hline $11 \_20135$ & $4 \mathrm{H}$ & 54.95 & 0.087 & 22.3 & 11.43 & 0.000 \\
\hline $11 \_10262$ & $4 \mathrm{H}$ & 54.95 & 0.128 & 43.31 & 9.57 & 0.000 \\
\hline 12_31462 & $4 \mathrm{H}$ & 54.95 & 0.132 & 28.24 & 7.24 & 0.000 \\
\hline 11_20450 & $4 \mathrm{H}$ & 54.95 & 0.055 & 17.91 & 4.37 & 0.016 \\
\hline 11_20412 & $4 \mathrm{H}$ & 54.95 & 0.077 & 46.22 & 4.28 & 0.017 \\
\hline SCRI_RS_168496 & $4 \mathrm{H}$ & 54.95 & 0.134 & 27.36 & 4.14 & 0.020 \\
\hline SCRI_RS_141730 & $4 \mathrm{H}$ & 54.95 & 0.160 & 33.58 & 4.09 & 0.020 \\
\hline SCRI_RS_228477 & $4 \mathrm{H}$ & 54.95 & 0.132 & 26.89 & 3.72 & 0.039 \\
\hline $11 \_10568$ & $4 \mathrm{H}$ & 54.95 & 0.138 & 41.22 & 3.69 & 0.039 \\
\hline 12_30839 & $4 \mathrm{H}$ & 54.95 & 0.037 & 28.11 & 3.50 & 0.053 \\
\hline $11 \_20020$ & $4 \mathrm{H}$ & 54.95 & 0.106 & 37.84 & 3.26 & 0.071 \\
\hline 11_10509 & $4 \mathrm{H}$ & 55.64 & 0.065 & 40.47 & 3.41 & 0.061 \\
\hline SCERI_RS_189180 & $4 \mathrm{H}$ & 57.32 & 0.136 & 47.09 & 3.49 & 0.054 \\
\hline SCRI_RS_148330 & $4 \mathrm{H}$ & 103.48 & 0.090 & 18.65 & 3.24 & 0.071 \\
\hline SCRI_RS_192689 & $4 \mathrm{H}$ & 103.58 & 0.017 & 40.27 & 4.34 & 0.016 \\
\hline $11 \_21035$ & $4 \mathrm{H}$ & 117.13 & 0.119 & 47.23 & 3.04 & 0.094 \\
\hline $12 \_11298$ & $5 \mathrm{H}$ & 111.56 & 0.003 & 11.69 & 5.18 & 0.004 \\
\hline SCRI_RS_188243 & $6 \mathrm{H}$ & 59.21 & 0.018 & 8.24 & 7.49 & 0.000 \\
\hline SCRI_RS_176650 & $6 \mathrm{H}$ & 59.21 & 0.010 & 20.41 & 4.56 & 0.012 \\
\hline SCRI_RS_186193 & $6 \mathrm{H}$ & 59.21 & 0.014 & 10.27 & 3.21 & 0.073 \\
\hline $12 \_11477$ & $7 \mathrm{H}$ & 78.07 & 0.003 & 10.07 & 3.23 & 0.071 \\
\hline 12_11536 & $7 \mathrm{H}$ & 78.07 & 0.003 & 10.07 & 3.23 & 0.071 \\
\hline $12 \_31000$ & $7 \mathrm{H}$ & 78.07 & 0.003 & 10.07 & 3.23 & 0.071 \\
\hline SCRI_RS_202130 & $7 \mathrm{H}$ & 133.84 & 0.006 & 35.81 & 4.47 & 0.013 \\
\hline 11_20847 & $7 \mathrm{H}$ & 145.68 & 0.009 & 40.95 & 3.55 & 0.052 \\
\hline 11_10687 & $7 \mathrm{H}$ & 146.03 & 0.012 & 40.54 & 3.4 & 0.061 \\
\hline 12_10677 & $7 \mathrm{H}$ & 150.36 & 0.019 & 10.81 & 3.07 & 0.091 \\
\hline SCRI_RS_208732 & N/A & N/A & 0.128 & 43.51 & 9.93 & 0.000 \\
\hline SCRI_RS_147636 & N/A & N/A & 0.124 & 44.12 & 8.74 & 0.000 \\
\hline $11 \_21017$ & N/A & N/A & 0.062 & 16.82 & 4.01 & 0.022 \\
\hline 12_20803 & N/A & N/A & 0.002 & 14.26 & 3.51 & 0.053 \\
\hline SCRI_RS_156237 & N/A & N/A & 0.039 & 31.62 & 3.35 & 0.064 \\
\hline SCRI_RS_133327 & N/A & N/A & 0.120 & 24.32 & 3.26 & 0.071 \\
\hline SCRI_RS_145381 & N/A & N/A & 0.002 & 48.78 & 3.19 & 0.074 \\
\hline SCRI_RS_146785 & N/A & N/A & 0.002 & 49.19 & 3.17 & 0.077 \\
\hline
\end{tabular}

a N/A indicates that the marker was not anchored to the consensus map.

b Genetic distances in centimorgans (cM).

c Phenotypic variation explained by individual markers.

d Minor allele frequency (MAF).

e $-\log 10(P$ value $)$ for each individual marker calculated from the QK mixed model.

f Positive false discovery rate (pFDR). 
resolution of the mapping in the Leger $\times$ CI 9831 DHL population this is only speculation.

We have possibly detected all the major and minor SFNB resistance QTL previously reported on barley chromosomes $2 \mathrm{H}$, $4 \mathrm{H}, 5 \mathrm{H}, 6 \mathrm{H}$, and $7 \mathrm{H}(17,20,23,39,45,68,69)$ and new QTL present on all seven barley chromosomes. Similarly, NFNB resistance QTL have been identified throughout the genome (33); however, resistance to both forms of the net blotch pathogen were rarely identified in similar locations $(20,39)$, suggesting that the majority of resistances are distinct for the different forms of $P$. teres and in regards to breeding, the two need to be treated as separate diseases. Growing barley cultivars with genetic resistance to SFNB and NFNB is the most sustainable strategy of disease management $(33,44)$. However, the diversity of virulence/avirulence genes within the pathogen populations and complexity of the interaction with host susceptibility targets and resistance genes requires robust genetic characterization of both the host and pathogen to understand the underlying genetic interactions involved. To date, only 11 different genotypes from the primary barley germplasm pool had been genetically characterized for SFNB resistance, thus deeper screening was required to identify diverse resistances or lack of functional susceptibility targets. This was accomplished in this study utilizing AM to capture diverse loci associated with SFNB resistance/susceptibility.

TABLE 4. Single nucleotide polymorphism markers significantly associated with resistance/susceptibility to Pyrenophora teres f. maculata isolate DEN 2.6

\begin{tabular}{|c|c|c|c|c|c|c|}
\hline Marker & $\mathrm{Chr}^{\mathrm{a}}$ & $\mathrm{cM}^{\mathrm{a}, \mathrm{b}}$ & $R^{2}(\%)^{\mathrm{c}}$ & $\mathrm{MAF}^{\mathrm{d}}$ & $P$ value & $\mathrm{pFDR}^{\mathrm{f}}$ \\
\hline 11_20792 & $1 \mathrm{H}$ & 88.25 & 0.015 & 31.689 & 3.02 & 0.141 \\
\hline 12_20878 & $2 \mathrm{H}$ & 69.00 & 0.086 & 5.135 & 3.11 & 0.127 \\
\hline SCRI_RS_127994 & $3 \mathrm{H}$ & 53.42 & 0.077 & 25.203 & 3.07 & 0.131 \\
\hline 11_21305 & $3 \mathrm{H}$ & 65.16 & 0.052 & 37.7 & 3.95 & 0.033 \\
\hline SCRI_RS_229623 & $3 \mathrm{H}$ & 150.19 & 0.029 & 16.55 & 3.38 & 0.088 \\
\hline $12 \_10014$ & $3 \mathrm{H}$ & 154.47 & 0.053 & 22.03 & 3.47 & 0.086 \\
\hline SCRI_RS_168580 & $4 \mathrm{H}$ & 53.77 & 0.031 & 16.22 & 3.39 & 0.088 \\
\hline SCRI_RS_184107 & $4 \mathrm{H}$ & 53.77 & 0.031 & 16.22 & 3.39 & 0.088 \\
\hline 12_30878 & $4 \mathrm{H}$ & 53.87 & 0.024 & 14.257 & 3.21 & 0.111 \\
\hline SCRI_RS_128723 & $4 \mathrm{H}$ & 54.66 & 0.147 & 30.95 & 7.51 & 0.000 \\
\hline SCRI_RS_155554 & $4 \mathrm{H}$ & 54.66 & 0.124 & 30.41 & 5.85 & 0.001 \\
\hline SCRI_RS_208828 & $4 \mathrm{H}$ & 54.66 & 0.148 & 37.43 & 5.49 & 0.002 \\
\hline SCRI_RS_221172 & $4 \mathrm{H}$ & 54.66 & 0.141 & 35.2 & 5.47 & 0.002 \\
\hline 11_20135 & $4 \mathrm{H}$ & 54.95 & 0.109 & 22.3 & 14.02 & 0.000 \\
\hline 11_10262 & $4 \mathrm{H}$ & 54.95 & 0.145 & 43.31 & 10.33 & 0.000 \\
\hline 11_20412 & $4 \mathrm{H}$ & 54.95 & 0.094 & 46.22 & 5.76 & 0.001 \\
\hline 11_20450 & $4 \mathrm{H}$ & 54.95 & 0.069 & 17.91 & 5.62 & 0.001 \\
\hline 12_31462 & $4 \mathrm{H}$ & 54.95 & 0.124 & 28.24 & 5.34 & 0.002 \\
\hline 11_20472 & $4 \mathrm{H}$ & 54.95 & 0.057 & 20.34 & 4.46 & 0.013 \\
\hline 12_30839 & $4 \mathrm{H}$ & 54.95 & 0.039 & 28.11 & 3.71 & 0.054 \\
\hline SCRI_RS_168496 & $4 \mathrm{H}$ & 54.95 & 0.130 & 27.36 & 3.42 & 0.088 \\
\hline SCRI_RS_141730 & $4 \mathrm{H}$ & 54.95 & 0.149 & 33.581 & 3.08 & 0.131 \\
\hline SCRI_RS_147712 & $4 \mathrm{H}$ & 59.22 & 0.097 & 17.43 & 3.97 & 0.033 \\
\hline SCRI_RS_163033 & $4 \mathrm{H}$ & 59.22 & 0.095 & 17.3 & 3.35 & 0.092 \\
\hline 11_20762 & $4 \mathrm{H}$ & 96.6 & 0.075 & 37.432 & 3.22 & 0.111 \\
\hline $12 \_10666$ & $4 \mathrm{H}$ & 96.99 & 0.075 & 38.51 & 3.30 & 0.099 \\
\hline 12_11298 & $5 \mathrm{H}$ & 111.56 & 0.001 & 11.69 & 4.19 & 0.021 \\
\hline SCRI_RS_188243 & $6 \mathrm{H}$ & 59.21 & 0.024 & 8.24 & 8.77 & 0.000 \\
\hline SCRI_RS_176650 & $6 \mathrm{H}$ & 59.21 & 0.014 & 20.41 & 5.32 & 0.002 \\
\hline SCRI_RS_186193 & $6 \mathrm{H}$ & 59.21 & 0.020 & 10.27 & 4.27 & 0.018 \\
\hline 11_21419 & $7 \mathrm{H}$ & 0.00 & 0.013 & 41.284 & 3.14 & 0.121 \\
\hline SCRI_RS_208732 & N/A & N/A & 0.144 & 43.51 & 10.17 & 0.000 \\
\hline SCRI_RS_147636 & N/A & N/A & 0.139 & 44.12 & 9.28 & 0.000 \\
\hline 11_21017 & N/A & N/A & 0.082 & 16.82 & 6.10 & 0.001 \\
\hline SCRI_RS_161627 & N/A & N/A & 0.015 & 9.12 & 3.62 & 0.063 \\
\hline SCRI_RS_114164 & N/A & N/A & 0.082 & 26.351 & 3.28 & 0.100 \\
\hline SCRI_RS_156237 & N/A & N/A & 0.041 & 31.622 & 3.18 & 0.113 \\
\hline SCRI_RS_168610 & N/A & N/A & 0.098 & 18.311 & 3.01 & 0.142 \\
\hline
\end{tabular}

${ }^{a}$ N/A indicates that the marker was not anchored to the consensus map.

b Genetic distances in centimorgans (cM).

c Phenotypic variation explained by individual markers.

${ }^{\mathrm{d}}$ Minor allele frequency (MAF).

e $-\log 10(P$ value $)$ for each individual marker calculated from the $\mathrm{QK}$ mixed model.

${ }^{f}$ Positive false discovery rate (pFDR).
A recent review of host specific toxins (also referred to as necrotrophic effectors) produced by the Pleosporales necrotrophic pathogens in the Dothideomycete class suggested that necrotrophic effectors (NE) predominantly interact with dominant host susceptibility gene products (59). These interactions followed the inversegene-for-gene model (16) or NE triggered susceptibility (NETS) model $(35,56)$, resulting in quantitative susceptibility to these pathogens which can also be viewed as quantitative recessive resistance. The reports of proteinaceous and nonproteinaceous toxins being produced by $P$. teres f. maculata and P. teres $\mathrm{f}$. teres (reviewed in Liu et al. 2011 [33]) as well as mapping of distinct $P$. teres f. teres virulence QTL targeting regions of dominant susceptibility in barley $(35,56)$, suggests that the NETS model may be at least partially responsible for virulence in $P$. teres $\mathrm{f}$. maculata. Thus, the accumulation of distinct NE genes spread throughout the genome of the pathogen that theoretically interact with host susceptibility genes, facilitates the pathogens ability to induce disease. The diversity of NEs within pathogen populations explains the variability in virulence of $P$. teres $\mathrm{f}$. maculata isolates collected from around the world and may explain why Tekauz (62) was unable to identify effective resistance sources against isolates collected in western Canada.

$P$. teres f. maculata collections from local and global fungal populations show wide variations for virulence on differential barley lines (reviewed in Liu et al. 2011 [33]). This indicates that the variability in virulence gives the pathogen the potential to shift the population toward the prevalence of NEs that target susceptibility factors within popular cultivars resulting in what appears to be virulence on the limited sources of resistance present $(2,7,30,33,42,56,62,70)$. The frequency of virulent genotypes in pathogen populations can rapidly increase as popular cultivars with incomplete resistance or lack of some susceptibility exert selection pressure. Also, these sexual pathogen populations allows for recombination of virulence genes giving rise to new possibly more virulent isolates containing several effectors that were selected for and brought together by recombination. Because of these complex interactions, breeding strategies focused on developing highly resistant lines must combine multiple loci, with some lacking host susceptibility targets and possibly others harboring active resistance loci. Knowledge of these host-pathogen genetic interactions and the genes/loci determining both lack of susceptibility and resistance is critical for intelligent deployment of SFNB resistant lines. These AM analyses provide very important information on these susceptibility/resistance loci but to effectively utilize new loci containing nonfunctional SFNB susceptibility targets and/or resistance from the $\mathrm{BCC}$, further genetic characterization of the host-pathogen genetic interactions through targeted biparental populations of both the host and pathogen is needed. We are further validating the distinct QTL identified by preparing DH and recombinant inbred line populations by crossing susceptible malting cultivars with highly resistant BCC accessions that we determined are missing the susceptibility targets or containing the major resistances. These populations will expedite the development of elite breeding lines that can be utilized in the development of resistant cultivars that can be grown in the upper Midwestern region of the United States and elsewhere, whether the mechanism is through the removal of susceptibility factors or the incorporation of resistance.

\section{ACKNOWLEDGMENTS}

This research was supported by funding from USDA-NIFA-AFRI grant number 2011-68002-30029 (T-CAP).

\section{LITERATURE CITED}

1. Agrama, H. A., Eizenga, G. C., and Yan, W. 2007. Association mapping of yield and its components in rice cultivars. Mol. Breed. 19:341-356. 
2. Arabi, M., Al-Safadi, I. E., and Charbaji, B. T. 2003. Pathogenic variation among isolates of Pyrenophora teres the causal agent of barley net blotch. J. Phytopathol. 151:376-382.

3. Aranzana, M. J., Kim, S., Zhao, K., Bakker, E., Horton, M., Jakob, K., Lister, C., Molitar, J., Shindo, C., Tang, C., Toomajian, C., Traw, B., Zheng, H., Bergelson, J., Dean, C., Marjoram, P., and Nordborg, M. 2005. Genome-wide association mapping in Arabidopsis identifies previously known flowering time and pathogen resistance genes. PLoS Genet. 1:e60.

4. Atwell, S., Huang, Y. S., Vilhajalmsson, B., Willems, G., Horton, M., Li, Y., Meng, D., Platt, A., Tarone, A. M., Hu, T. T., Jiang, R., Muliyati, N. W., Zhang, X., Amer, M. A., Baxter, I., Brachi, B., Chory, J., Dean, C., Debieu, M., de Meaux, J., Ecker, J. R., Faure, N., Kniskern, J. M., Jones, J. D. G., Michael, T., Nemri, A., Roux, F., Salt, D. E., Tanf, C., Todesco, M., Traw, M. B., Weigel, D., Marjoram, P., Borevitz, J. O., Bergelson, J., and Nordborg, M. 2010. Genome-wide association study of 107 phenotypes in Arabidopsis thaliana inbred lines. Nature 465:627-631.

5. Beattie, A. D., Edney, M. J., Scoles, G. J., and Rossnagel, B. G. 2010. Association mapping of malting quality data from western Canadian tworow barley cooperative trials. Crop Sci. 50:1649-1663.

6. Berger, G. L., Liu, S., Hall, M. D., Chao, S., Muehlbauer, G. J., Baik, B.-K., Steffenson, B., and Griffey, C. A. 2013. Marker-trait associations in Virginia Tech winter barley identified using genome-wide mapping. Theor. Appl. Genet. 126:693-710.

7. Bockelman, H. E., Sharp, E. L., and Bjarko, M. E. 1983. Isolates of Pyrenophora teres from Montana and the Mediterranean region that produce spot type lesions on barley. Plant Dis. 67:696-697.

8. Breseghello, F., and Sorrells, M. E. 2006. Association mapping of kernel size and milling quality in wheat (Triticum aestivum L.) cultivars. Genetics 172:1165-1177.

9. Brown, M. P., Steffenson, B. J., and Webster, R. K. 1993. Host range of Pyrenophora teres f. teres isolates from California. Plant Dis. 77:942-947.

10. Earl, D. A., and von Holdt, B. M. 2011. STRUCTURE HARVESTER: A website and program for visualizing STRUCTURE output and implementing the Evanno method. Conservation Genetics Resources 4:1-3.

11. Ehrenreich, I. M., Hanzawa, Y., Chou, L., Roe, J. L., Kover, P. X., and Purugganan, M. D. 2009. Candidate gene association mapping of Arabidopsis flowering time. Genetics 183:325-335.

12. Evanno, G., Regnaut, S., and Goudet, J. 2005. Detecting the number of clusters of individuals using the software STRUCTURE: A simulation study. Mol. Ecol. 14:2611-2620.

13. Faris, J. D., Zhang, Z., Lu, H., Lu, S., Reddy, L., Cloutier, S., Fellers, J. P., Meinhardt, S. W., Rasmussen, J. B., Xu, S. S., Oliver, R. P., Simons, K. J., and Friesen, T. L. 2010. A unique wheat disease resistance-like gene governs effector-triggered susceptibility to necrotrophic pathogens. Proc. Natl. Acad. Sci. USA 107:13544-13549.

14. Flint, J., and Mackay, T. F. 2009. Genetic architecture of quantitative traits in mice, flies, and humans. Genome Res. 19:723-733.

15. Flint-Garcia, S. A., Thornsberry, J. M., and Buckler, E. S. 2003. Structure linkage disequilibrium in plants. Annu. Rev. Plant Biol. 54:357-374.

16. Friesen, T. L., and Faris, J. D. 2010. Characterization of the wheatStagonospora nodorum disease system: What is the molecular basis of this quantitative necrotrophic disease interaction? Can. J. Plant Pathol. 32: 20-28.

17. Friesen, T. L., Faris, J. D., Lai, Z., and Steffenson, B. J. 2006. Identification and chromosomal location of major genes for resistance to Pyreonophora teres in a doubled-haploid barley population. Genome 49: 855-859.

18. Friesen, T. L., Faris, J. D., Solomon, P. S., and Oliver, R. P. 2008. Host specific toxins: effectors of necrotrophic pathogenicity. Cell. Microbiol. 10:1421-1428.

19. Ghavami, F., Elias, E. M., Mamidi, S., Ansari, O., Sargolzaei, M., Adhikari, T., Mergoum, M., and Kianian, S. F. 2011. Mixed model association mapping for Fusarium head blight resistance in Tunisian-derived durum wheat populations. G3: Genes Genomes Genetics 1:209-218.

20. Grewal, T. S., Rossnagel, B. G., Pozniak, C. J., and Scoles, G. J. 2008. Mapping quantitative trait loci associated with barley net blotch resistance. Theor. Appl. Genet. 116:529-539.

21. Gupta, S., and Loughman, R. 2001. Current virulence of Pyrenophora teres on barley in Western Australia. Plant Dis. 85:960-966.

22. Gutierrez, L., Cuesta-Marcos, A., Castro, A. J., von Zitzewitz, J., Schmitt, M., and Hayes, P. M. 2010. Association mapping of malting quality quantitative trait loci in winter barley: Positive signals from small germplasm arrays. Plant Genome 4:256-272.

23. Ho, K. M., Tekauz, A., Choo, T. M., and Martin, R. A. 1996. Genetic studies on net blotch resistance in a barley cross. Can. J. Plant Sci. 76: 715-719.

24. Honsdorf, N., Becker, H. C., and Ecke, W. 2010. Association mapping for phenological, morphological, and quality traits in canola quality winter rapeseed (Brassica napus L.). Genetics 53:899-907.
25. Ivandic, V., Hackett, C. A., Nevo, E., Keith, R., Thomas, W. T. B., and Forster, B. P. 2002. Analysis of simple sequence repeats (SSRs) in wild barley from the Fertile Crescent: Associations with ecology, geography and flowering time. Plant Mol. Biol. 48:511-527.

26. Ivandic, V., Thomas, W. T. B., Nevo, E., Zhang, Z., and Forster, B. P. 2003. Associations of simple sequence repeats with quantitative trait variation including biotic and abiotic stress tolerance in Hordeum spontaneum. Plant Breed. 122:300-304.

27. Jayasena, K. W., van Burgel, A., Tanaka, K., Mejewski, J., and Loughman, R. 2007. Yield reduction in barley in relation to spot-type net blotch. Australas. Plant Pathol. 36:429-433.

28. Jordan, V. W., and Allen, E. 1984. Barley net blotch: Influence of straw disposal and cultivation methods on inoculum potential, and on incidence and severity of autumn disease. Plant Pathol. 33:547-559.

29. Karki, C. B., and Sharp, E. L. 1986. Pathogenic variation in some isolates of Pyrenophora teres f. sp. maculata on barley. Plant Dis. 70:684-687.

30. Khan, T. N., and Tekauz, A. 1982. Occurrence and pathogenicity of Dreshslera teres isolates causing spot-type symptoms on barley in Western Australia. Plant Dis. 66:423-425.

31. Kraakman, A. T. W., Rients, E. N., Petra, M. M., Van den Berg, M., Stam, P., and Van Eeuwijk, F. A. 2004. Linkage disequilibrium mapping of yield and yield stability in modern spring barley cultivars. Genetics 168: 435-446.

32. Kump, K. L., Bradbury, P. J., Wisser, R. J., Buckler, E. S., Belcher, A. R., Oropeza-Rosas, M. A., Zwonitzer, J. C., Kresovich, S., McMullen, M. D., Ware, D., Balint-Kurti, P. J., and Holland, J. B. 2011. Genome-wide association study of quantitative resistance to southern leaf blight in the maize nested association mapping population. Nat. Genet. 43:163-168.

33. Liu, Z. H., Ellwood, S. R., Oliver, R. P., and Friesen, T. L. 2011. Pyrenophora teres: Profile of an increasingly damaging barley pathogen. Mol. Plant Pathol. 12:1-19.

34. Liu, Z. H., and Friesen, T. L. 2010. Identification of Pyrenophora teres f. maculata, causal agent of spot type net blotch of barley in North Dakota. Plant Dis. 94:480.

35. Liu, Z. H., Holmes, D. J., Faris, J. D., Chao, S., Brueggeman, R. S., Edwards, M. C., and Friesen, T. L. 2015. Necrotrophic effectortriggered susceptibility (NETS) underlies the barley-Pyrenophora teres f. teres interaction specific to chromosome 6H. Mol. Plant Pathol. 16: 188-200.

36. Malosetti, M., van der Linden, C. G., Vosman, B., and van Eeuwijk, F. A. 2007. A mixed-model approach to association mapping using pedigree information with an illustration of resistance to Phytophthora infestans in potato. Genetics 175:879-889.

37. Mamidi, S., Chikara, S., Goos, R. J., Hyten, D. L., Annam, D., Moghaddam, S. M., Lee, R. K., Cregan, P. B., and McClean, P. E. 2011. Genome-wide association analysis identifies candidate genes associated with iron deficiency chlorosis in soybean. Plant Genome 4:154-160.

38. Mamidi, S., Lee, R. K., Goos, J. R., and McClean, P. E. 2014. Genomewide association studies identifies seven major regions responsible for iron deficiency chlorosis in soybean (Glycine max). PLoS ONE 9: e107469.

39. Manninen, O. M., Jalli, M., Kalender, R., Schulman, A., Afanasenko, O., and Robinson, J. 2006. Mapping of major spot-type and net-type netblotch resistance genes in the Ethiopian barley line CI9819. Genome 49: 1564-1571.

40. Massman, J., Cooper, B., Horsley, R., Neate, S., Dill-Macky, R., Chao, S., Dong, Y., Muehlbauer, G., and Smith, K. 2011. Genome-wide association mapping of Fusarium head blight resistance in contemporary barley breeding germplasm. Mol. Breed. 27:439-454.

41. Mathre, D. E. 1997. Compendium of Barley Diseases, 2nd ed. American Phytopathological Society, St. Paul, MN.

42. McLean, M. S., Howlett, B. J., and Hollaway, G. J. 2009. Epidemiology and control of spot form of net blotch (Pyrenophora teres f. maculata) of barley, a review. Crop Pasture Sci. 60:303-315.

43. McLean, M. S., Howlett, B. J., and Hollaway, G. J. 2010. Spot form of net blotch, caused by Pyrenophora teres f. maculata, is the most prevalent foliar disease of barley in Victoria, Australia. Australas. Plant Pathol. 39: 46-49.

44. McLean, M. S., Howlett, B. J., Turkington, T. K., Platz, G. J., and Hollaway, G. J. 2012. Spot form of net blotch resistance in a diverse set of barley lines in Australia and Canada. Plant Dis. 96:569-576.

45. Molnar, S. J., James, L. E., and Kasha, K. J. 2000. Inheritance and RAPD tagging of multiple genes for resistance to net blotch in barley. Genome 43:224-231.

46. Muñoz-Amatriaín, M., Cuesta-Marcos, A., Endelman, J. B., Comadran, J., Bonman, J. M., Bockelman, H. E., Chao, S., Russell, J., Waugh, R., Hayes, P. M., and Muehlbauer, G. J. 2014. The USDA barley core collection: Genetic diversity, population structure, and potential for genomewide association studies. PLoS ONE 9:e94688. 
47. Murray, G. M., and Brennan, J. P. 2010. Estimating disease losses to the Australian barley industry. Australas. Plant Pathol. 39:85-96.

48. Myles, S., Peiffer, J., Brown, P. J., Ersoz, E. S., Zhang, Z., Costich, D. E., and Buckler, E. D. 2009. Association mapping: Critical consideration shift from genotyping to experimental design. Plant Cell 21:2194-2202.

49. Neupane, A., Tamang, P., Brueggeman, R., and Friesen, T. 2015. Evaluation of a barley core collection for spot form net blotch reaction reveals distinct genotype-specific pathogen virulence and host susceptibility. Phytopathology 105:509-517.

50. Oliver, R. P., Friesen, T. L., Faris, J. D., and Solomon, P. S. 2012. Stagonospora nodorum: From pathology to genomics and host resistance. Annu. Rev. Phytopathol. 50:23-43.

51. Pakniyat, H., Powell, W., Baird, E., Handley, L. L., Robinson, D., Scrimgeor, C. M., Nevo, E., Hackett, C. A., Caligari, P. D. S., and Forster, B. P. 1997. AFLP variation in wild barley (Hordeum spontaneum C. Koch) with reference to salt tolerance and associated ecogeography. Genome 40:332-341.

52. Qamar, M. A., Liu, Z. H., Faris, J. D., Chao, S., Edwards, M. C., Lai, Z., Franckowiak, J. D., and Friesen, T. L. 2008. A region of barley chromosome $6 \mathrm{H}$ harbors multiple major genes associated with net type net blotch resistance. Theor. Appl. Genet. 117:1261-1270.

53. Remington, D. L., Thornsberry, J. M., Matsuoka, Y., Wilson, L. M., Whitt, S. R., Doebly, J., Kresovich, S., Goodman, M. M., and Buckler, E. S., IV. 2001. Structure of linkage disequilibrium and phenotypic associations in the maize genome. PNAS 98:11479-11484.

54. Roy, J. K., Smith, K. P., Muehlbauer, G. J., Chao, S., Close, T. J., and Steffenson, B. J. 2010. Association mapping of spot blotch resistance in wild barley. Mol. Breed. 26:243-256.

55. Scheet, P., and Stephens, M. 2006. A fast and flexible statistical model for large-scale population genotype data: Applications to inferring missing genotypes and haplotypic phase. Am. J. Hum. Genet. 78:629-644.

56. Shjerve, R. A., Faris, J. D., Brueggeman, R. S., Yan, C., Zhu, Y., Koladia, V., and Friesen, T. L. 2014. Evaluation of Pyrenophora teres f. teres mapping population reveals multiple independent interactions with a region of barley chromosome 6H. Fungal Genet. Biol. 70:104-112.

57. Smedegård-Petersen, V. 1971. Kgl. Vet. Landbohojsk. Arsskr., Pyrenophora teres f. maculata f. nov. and Pyrenophora teres f. teres on barley in Denmark. Copenhagen, Denmark, Royal Veterinary and Agricultural University, Pages 124-144.

58. Steffenson, B. J., and Webster, R. K. 1992. Pathotype diversity of Pyrenophora teres f. teres on barley. Phytopathology 82:170-177.

59. Stergiopoulos, I., Collemare, J., Mehrabi, R., and De Wit, P. J. G. M. 2013. Phytotoxic secondary metabolites and peptides produced by plant pathogenic Dothideomycete fungi. FEMS Microbiol. Rev. 37:67-93.

60. Stich, B., and Melchinger, A. E. 2009. Comparison of mixed-model approaches for association mapping in rapeseed, potato, sugar beet, maize, and Arabidopsis. BMC Genomics 10:94.

61. Storey, J. D. 2002. A direct approach to false discovery rates. J. R. Stat. Soc. Series B Stat. Methodol. 64:479-498.

62. Tekauz, A. 1990. Characterization and distribution of pathogenic variation in Pyrenophora teres f. teres and $P$. teres f. maculata from western Canada. Can. J. Plant Pathol. 12:141-148.

63. Tommasini, L., Schnurbusch, T., Fossati, D., Mascher, F., and Keller, B. 2007. Association mapping of Stagonospora nodorum blotch resistance in modern European winter wheat varieties. Theor. Appl. Genet. 115: 697-708

64. Tuohy, J. M., Jalli, M., Cooke, B. M., and Sullivan, E. O. 2006. Pathogenic variation in populations of Drechslera teres f. teres and D. teres f. maculata and differences in host cultivar responses. Eur. J. Plant Pathol. 116: $177-185$.

65. Von Zitzewitz, J., Cuesta-Marcos, A., Condon, F., Castro, A., Chao, S., Corey, A., Filichkin, T., Fisk, S., Gutierrez, L., Haggard, K., Karsai, I., Muehlbauer, G., Smith, K., Veisz, O., and Hayes, P. 2011. The genetics of winter hardiness in barley: Perspectives from genome-wide association mapping. Plant Genome 4:76-91.

66. Wang, J., McClean, P. E., Lee, R., Goos, R. J., and Helms, T. 2008. Association mapping of iron deficiency chlorosis loci in soybean (Glycine $\max$ L. Merr.) advanced breeding lines. Theor. Appl. Genet. 116:777-787.

67. Weber, A. L., Briggs, W. H., Rucker, J., Baltazar, B. M., Sanchez-Gonzalez, J. D., Feng, P., Buckler, E. S., and Doebley, J. F. 2008. The genetic architecture of complex traits in teosinte (Zea mays ssp. paryglumis): New evidence from association mapping. Genetics 180: 1221-1232.

68. Williams, K. J., Lichon, A., Gianquitto, P., Kretschmer, J. M., Karakousis, A., Manning, S., Langridge, P., and Wallwork, H. 1999. Identification and mapping of a gene conferring resistance to the spot form of net blotch (Pyrenophora teres f. maculata) in barley. Theor. Appl. Genet. 99: 323-327.

69. Williams, K. J., Platz, G. J., Barr, A. R., Cheong, J., Willsmore, K., Cakir, M., and Wallwork, H. 2003. A comparison of the genetics of seedling and adult plant resistance to the spot form of net blotch (Pyrenophora teres $\mathrm{f}$. maculata). Aust. J. Agric. Res. 54:1387-1394.

70. Wu, H.-L., Dunkle, L. D., and Ciufetti, L. M. 2003. Genetic variation for virulence and RFLP markers in Pyrenophora teres. Can. J. Plant Pathol. 25:82-90.

71. Youcef-Benkada, M., Bendahmane, B. S., Sy, A. A., Barrault, G., and Albertini, L. 1994. Effects of inoculation of barley inflorescences with Drechslera teres upon the location of seed-borne inoculum and its transmission to seedlings as modified by temperature and soil moisture. Plant Pathol. 43:350-355.

72. Yu, J., Pressoir, G., Briggs, W. H., Bi, I. V., Yamasaki, M., Doebley, J. F., McMullen, M. D., Gaut, B. S., Nielsen, D. M., Holland, J. B., Kresovich, S., and Buckler, E. S. 2006. A unified mixed-model method for association mapping that accounts for multiple levels of relatedness. Nat. Genet. 38:203-208.

73. Zhao, K., Aranzana, M. J., Kim, S., Lister, C., Shindo, C., Tang, C., Toomajian, C., Zheng, H., Dean, C., Marjoram, P., and Nordberg, M. 2007. An Arabidopsis example of association mapping in structured samples. PLoS Genet. 3:e4.

74. Zhou, X., and Stephens, M. 2012. Genome-wide efficient mixed-model analysis for association studies. Nat. Genet. 44:821-824.

75. Zhu, C., Gore, M., Buckler, E. S., and Yu, J. 2008. Status and prospects of association mapping in plants. Plant Genome 1:5-20.

76. Zou, J., Jiang, C., Cao, Z., Li, R., Long, Y., Chen, S., and Meng, J. 2010. Association mapping of seed oil content in Brassica napus and comparison with quantitative trait loci identified from linkage mapping. Genome 53:908-916 